oxide, nitroglycerin, and prostaglandin infusions. Right ventricular function on echocardiography improved commensurate with decrease central venous pressure to the 12 $\mathrm{mm} \mathrm{Hg}$ range and extubation on day 8 .

Catheterization with biopsy was done on postoperative day 35. The reconstructed right internal jugular vein was used for vascular access. The right heart pressures were mildly elevated and histologic examination demonstrated no rejection. The patient was discharged several days later.

The patient remains well without graft dysfunction or rejection 2 months after transplantation.

\section{DISCUSSION}

The Berlin Heart provides long-term support, consuming fewer blood products and allowing extubation and reversal of debilitation not possible with ECMO. ${ }^{3,4}$ Use of the Berlin Heart in infants with single ventricle physiology has been rarely reported with no reports of successful transplantation to hospital discharge. ${ }^{1,2}$ Provision of systemic and pulmonary circulation with a single ventricular assist device is challenging. The technique we describe worked well in our case and may be useful in similar situations.

\section{References}

1. Chu MW, Sharma K, Tchervenkov CI, Jutras LF, Lavoie J, Shemie SD, et al. Berlin Heart ventricular assist device in a child with hypoplastic left heart syndrome. Ann Thorac Surg. 2007;83:1179-81.

2. Nathan M, Baird C, Fynn-Thompson F, Almond C, Thiagarajan R, Laussen P, et al. Successful implantation of a Berlin Heart biventricular assist device in a failing single ventricle. J Thorac Cardiovasc Surg. 2006;131:1407-8.

3. Stiller B, Hetzer R, Weng Y, Hummel M, Hennig E, Nagdyman N, et al. Heart transplantation in children after mechanical circulatory support with pulsatile pneumatic assist device. J Heart Lung Transplant. 2003;22:1201-8.

4. Stiller B, Lemmer J, Merkle F, Alexi-Meskishvili V, Weng Y, Hubler M, et al. Consumption of blood products during mechanical circulatory support in children: comparison between ECMO and a pulsatile ventricular assist device. Intensive Care Med. 2004;30:1814-20.

\title{
Modified perfusion technique for patients with renal cell carcinoma infiltrating the inferior vena cava
}

\author{
Gianluigi Bisleri, MD, ${ }^{\mathrm{a}}$ Paolo Piccoli, MD, ${ }^{\mathrm{a}}$ Sergio Cosciani Cunico, MD, ${ }^{\mathrm{b}}$ and Claudio Muneretto, MD, ${ }^{\mathrm{a}}$ Brescia, Italy
}

The surgical removal of renal cell carcinoma with thrombus extension in the inferior vena cava (IVC) and right atrium has been extensively described by means of a combined abdominal and thoracic approach with the aid of cardiopulmonary bypass and deep hypothermic circulatory arrest. $^{1-3}$

In an effort to further reduce the potential complications of such a perfusion technique (especially in terms of postoperative bleeding), we developed a simple modification of the circulatory support to provide continuous antegrade perfusion of the supra-aortic vessels during systemic circulatory arrest with moderate hypothermia.

\section{CLINICAL SUMMARY}

A 71-year-old woman was admitted to the Division of Urology at the University of Brescia Medical School after prolonged hematuria. Multislice abdominal computed to-

\footnotetext{
From the Divisions of Cardiac Surgery ${ }^{\mathrm{a}}$ and Urology, ${ }^{\mathrm{b}}$ University of Brescia Medical School, Brescia, Italy.

Received for publication Jan 31, 2008; accepted for publication Feb 10, 2008.

Address for reprints: Gianluigi Bisleri, MD, Cardiochirurgia SSVD-Spedali Civili,

P.le Spedali Civili, 1, 25123 Brescia, Italy (E-mail: gianluigi.bisleri@gmail.com).

J Thorac Cardiovasc Surg 2009;137:e42-4

$0022-5223 / \$ 36.00$

Copyright (c) 2009 by The American Association for Thoracic Surgery

doi:10.1016/j.jtcvs.2008.02.046
}

mography evaluation evidenced a huge neoplastic plurifocal mass in the left kidney, with a neoplastic thrombus infiltrating the main left renal vein and the IVC close to the suprahepatic veins. The diameter of the mass in the IVC at its maximum was approximately $6 \mathrm{~cm}$ (Figure 1). An echoDoppler evaluation of the IVC confirmed a cephalad extension of the mass just below the origin of the suprahepatic veins (with an overall distance from the right atrium of $3 \mathrm{~cm}$ ). Bone scintigraphy, multislice thoracic, and cerebral computed tomography scans did not detect any metastatic diffusion of the disease. The patient was therefore scheduled to undergo a combined procedure of left nephrectomy and IVC thrombus evacuation under cardiopulmonary bypass with hypothermic arrest.

After exposure of the kidney, its vascular structures, and the IVC up to the diaphragm, conventional sternotomy and pericardial opening were performed, exposing the aortic arch and supra-aortic branches up to the left subclavian artery. The ascending aorta was cannulated in the conventional fashion while a cannulation of both the right atrium and the superior vena cava (with a Y-connection to the main venous line) was carried out (Figure 2). A vent line was also placed in the left ventricle through the right superior pulmonary vein. Once the patient was on full cardiopulmonary bypass, systemic cooling to $25^{\circ} \mathrm{C}$ was achieved, the ascending aorta 


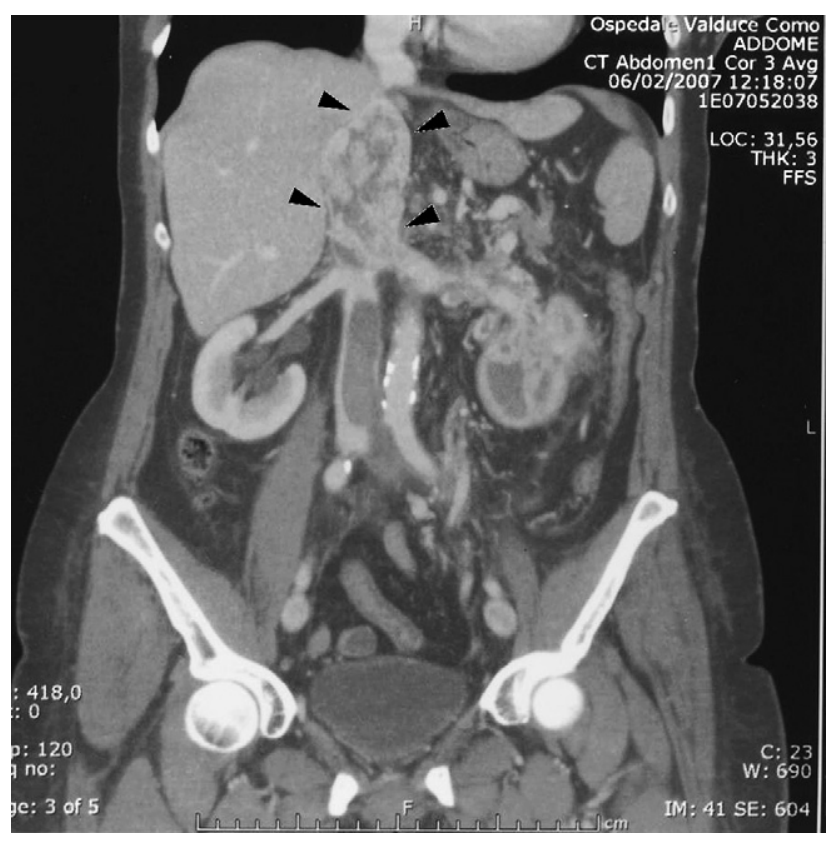

FIGURE 1. The neoplastic mass (arrowheads) from the left kidney infiltrating the IVC on computed tomography scan. was clamped, and antegrade cold crystalloid cardioplegia was administered. Then, the aortic arch was also clamped between the left common carotid artery and the left subclavian artery, the cannula in the right atrium was removed (clamping the line before the $\mathrm{Y}$-connection), a tape around the superior vena cava was snared down to obtain full venous drainage from the supra-aortic regions of the body, and perfusion at $1000 \mathrm{~mL} / \mathrm{min}$ was started through the aortic cannula (Figure 2).

While the IVC was widely opened, a concomitant right atriotomy was performed for visual inspection during thrombus removal. A complete excision of the neoplastic thrombus was achieved within 35 minutes without any embolization to the heart macroscopically detectable through the right atriotomy; then both the IVC and the right atrium were sutured. The cannula in the right atrium was reinserted, both clamps (in the ascending aorta and aortic arch) were removed, and cardiopulmonary bypass was reinstituted.

Once the patient had been weaned from extracorporeal circulation and protamine had been administered, nephrectomy was completed in the conventional fashion. No major complications occurred during the operation, and the patient was transferred back to the ward on postoperative day 3 .

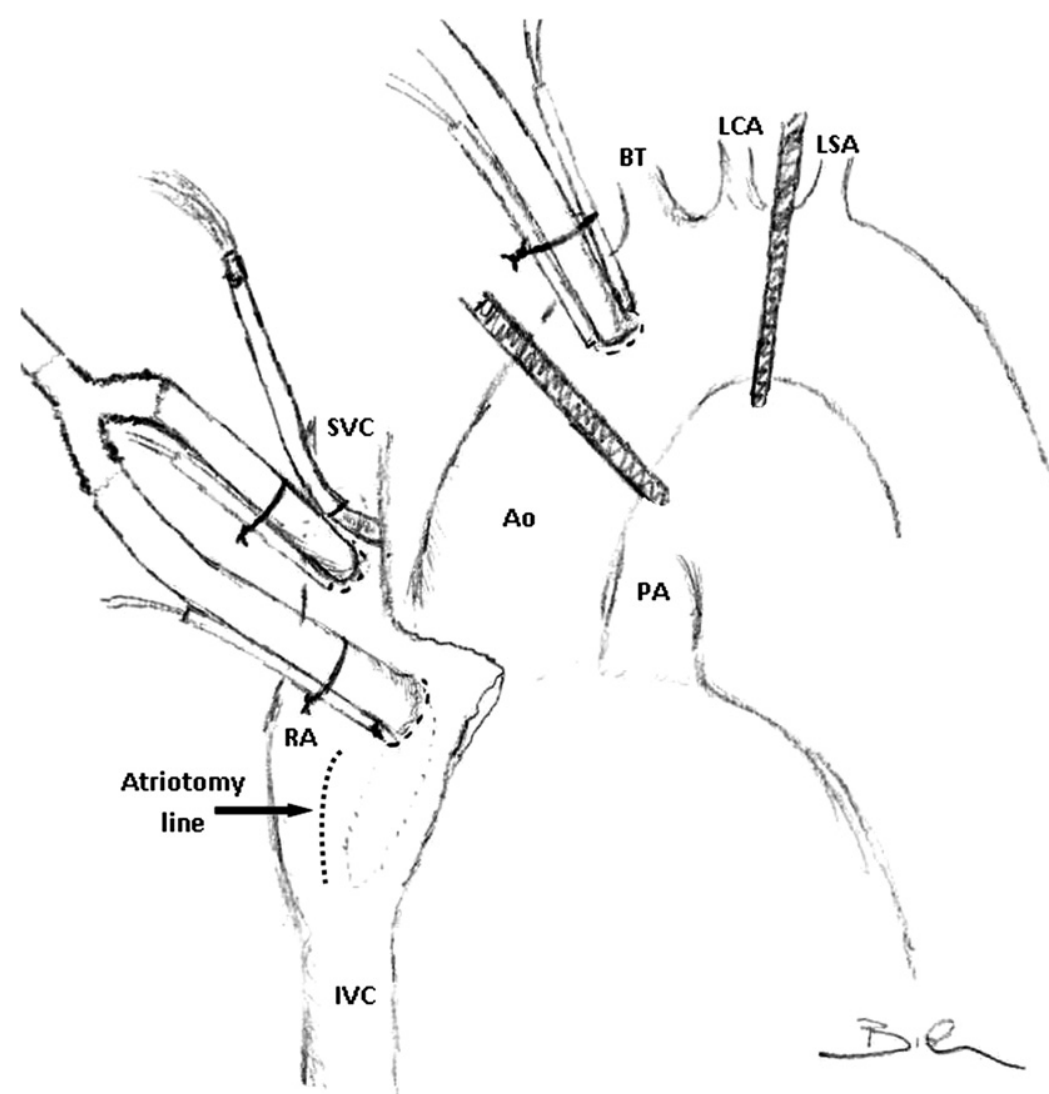

FIGURE 2. Schematic drawing of the innovative perfusion technique used. $A o$, Aorta; $P A$, pulmonary artery; $B T$, brachiocephalic trunk; $L C A$, left common carotid artery; $L S A$, left subclavian artery; $R A$, right atrium; $S V C$, superior vena cava; $I V C$, inferior vena cava. 


\section{DISCUSSION}

Although several surgical options have been widely established in the treatment of renal cell carcinoma extending into the IVC, whenever a potential involvement of the right atrium is suspected, the use of cardiopulmonary bypass with hypothermic arrest is usually adopted, albeit such technique yields potential risks, mainly in terms of coagulopathy. ${ }^{4}$

Because the huge dimensions and extension close to the right atrium of the neoplastic thrombus could have made its removal potentially cumbersome and therefore significantly prolonged the duration of hypothermic circulatory arrest, a novel perfusion strategy was adopted to allow continuous perfusion of the supra-aortic vessels during systemic circulatory arrest. Therefore, as described in the present report, the cardiopulmonary bypass temperature can be maintained at a greater degree than conventional hypothermic circulatory arrest $\left(\sim 18^{\circ} \mathrm{C}\right)$. Moreover, the described modification is cost-effective, without consistent modifications to the cardiopulmonary bypass circuit.

\section{CONCLUSIONS}

Although further clinical experience is warranted to confirm the encouraging results of our preliminary case, we believe this simple modification could represent a useful tool that adds to the surgical armamentarium for the treatment of renal cell carcinoma with intra-atrial thrombus.

\section{References}

1. Novick AC, Cosgrove DM. Surgical approach for removal of renal cell carcinoma extending into the vena cava and the right atrium. J Urol. 1980;123:947-50.

2. Paul JG, Rhodes MB, Skow JR. Renal cell carcinoma presenting as right atrial tumor with successful removal using cardiopulmonary bypass. Ann Surg. 1975;181:471-3.

3. Vaidya A, Ciancio G, Soloway M. Surgical techniques for treating a renal neoplasm invading the inferior vena cava. J Urol. 2003;169:435-44.

4. Harrington DK, Fragomeni F, Bonser RS. Cerebral perfusion. Ann Thorac Surg. 2007;83:S799-804.

\title{
Latero-lateral slide tracheoplasty for upper airway stenosis: An 8-year follow-up
}

\author{
Erdal Tasci, MD, ${ }^{\mathrm{a}}$ Halil Ciftci, MD, ${ }^{\mathrm{a}}$ Farzin Periovi, MD, ${ }^{\mathrm{b}}$ and Cemal Asim Kutlu, MD, FETCS, ${ }^{\mathrm{a}}$ Istanbul, Turkey
}

Since slide tracheoplasty (ST) was defined in $1989,{ }^{1}$ the scope of the technique has been further extended, as evidenced by reported cases of satisfactory outcomes. ST has been used for almost all types of long-segment tracheal stenosis, including "bilateral main bronchus stenosis", and "congenital laryngeal atresia (slide thyrocricotracheoplasty).,"3 We slightly modified the original technique and performed latero-lateral ST in a patient who presented with an acquired long-segmental stenosis. We report the patients' long-term follow-up.

\section{CLINICAL SUMMARY}

A 46-year-old man presented with a long-segment stenosis involving the subglottic area and proximal trachea caused by tracheobronchopathia osteochondroplastica. Spirometry showed a forced expiratory volume in 1 second of $1.46 \mathrm{~L}$ $(43 \%$ predicted) and a forced vital capacity of $3.06 \mathrm{~L}$

From the Department of Thoracic Surgery, Sureyyapasa Chest Diseases and Chest Surgery Teaching and Research Hospital, ${ }^{\mathrm{a}}$ Istanbul, Turkey; and Medica Imaging Centre, ${ }^{\mathrm{b}}$ Istanbul, Turkey.

Received for publication Feb 5, 2008; accepted for publication March 20, 2008.

Address for reprints: Cemal Asim Kutlu, MD, FETCS, Medkon, Hakki Yeten Cad. 12/

12, Şisli 34394, Istanbul, Turkey (E-mail: cakutlu@tnn.net).

J Thorac Cardiovasc Surg 2009;137:e44-6

$0022-5223 / \$ 36.00$

Copyright (c) 2009 by The American Association for Thoracic Surgery doi:10.1016/j.jtcvs.2008.03.041
( $81 \%$ predicted). Bronchoscopy relieved that the stenosis involved the subglottic area and proximal half of the trachea. Modified ST was undertaken via median sternotomy, and the anterior surface of the trachea was exposed to adjust the oblique (right to left) and longitudinal tracheal cuts along the stenosis. The longitudinal cut on the lateral surface of the proximal tracheal segment was extended superiorly up to the thyroid cartilage; the distal segment was then slid up after trimming both margins. Contrary to our routine technique for anastomosis, the cartilaginous part of the trachea was anastomosed with polyglycolic acid using an interrupted suture technique because of the thick and calcified tracheal wall.

Postoperatively, the main concern was the suture line healing in the oldest patient undergoing ST among the reported patients. Bronchoscopy was performed 2 times for bronchial toilet in the early postoperative course. This case was reported 15 months after the surgery when the patient had resumed his normal life without any respiratory problems or restrictions in his daily activities. ${ }^{4}$ Since then, he has not required any hospitalization, and chest x-rays taken by his primary physician showed no abnormality. $\mathrm{He}$ did not receive any medication, including bronchodilators and steroids. We invited him to our outpatient clinic 8 years after the operation to investigate the long-term results of the operation. On examination, no abnormality 